Provided for non-commercial research and education use. Not for reproduction, distribution or commercial use.

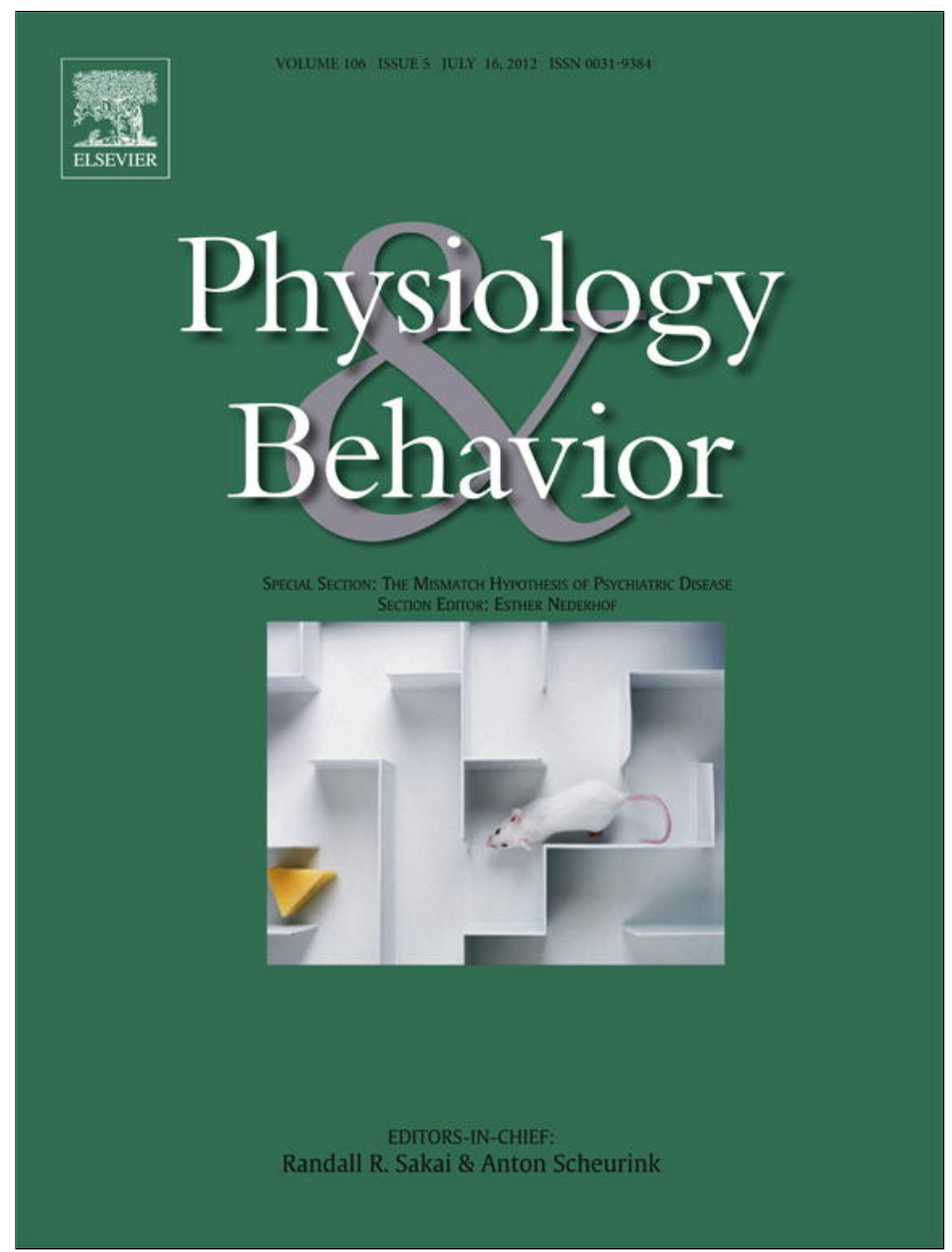

This article appeared in a journal published by Elsevier. The attached copy is furnished to the author for internal non-commercial research and education use, including for instruction at the authors institution and sharing with colleagues.

Other uses, including reproduction and distribution, or selling or licensing copies, or posting to personal, institutional or third party websites are prohibited.

In most cases authors are permitted to post their version of the article (e.g. in Word or Tex form) to their personal website or institutional repository. Authors requiring further information regarding Elsevier's archiving and manuscript policies are encouraged to visit:

http://www.elsevier.com/copyright 


\title{
Within-litter variation in maternal care received by individual pups correlates with adolescent social play behavior in male rats
}

\author{
F.N. van Hasselt ${ }^{\text {a }}$, J.M. Tieskens ${ }^{\text {a }}$, V. Trezza ${ }^{\text {b,c }}$, H.J. Krugers ${ }^{\text {a }}$, L.J.M.J. Vanderschuren ${ }^{\text {b,d,* }}$, M. Joëls ${ }^{\text {b, } * *}$ \\ a SILS-CNS, University of Amsterdam, Amsterdam, The Netherlands \\ ${ }^{\mathrm{b}}$ Department of Neuroscience and Pharmacology, Rudolf Magnus Institute of Neuroscience, University Medical Center Utrecht, Utrecht, The Netherlands \\ c Department of Biology, University Roma Tre, Rome, Italy \\ ${ }^{\mathrm{d}}$ Department of Animals in Science and Society, Division of Behavioral Neuroscience, Faculty of Veterinary Medicine, Utrecht University, Utrecht, The Netherlands
}

\section{A R T I C L E I N F O}

\section{Article history:}

Received 23 September 2011

Received in revised form 10 December 2011

Accepted 12 December 2011

\section{Keywords:}

Maternal care

Stress

Reward

Social play behavior

Postnatal development

\begin{abstract}
A B S T R A C T
Maternal care represents an essential environmental factor during the first post-natal week(s) of rodents and is known to have lasting consequences for neuronal structure, brain function as well as behavioral outcome later in life, including social functions and reward-related processes. Previous experiments have shown that the amount of maternal care received by individual pups varies substantially, even within one litter. During adolescence, mammals display high levels of social play behavior, a rewarding form of social interaction that is of great importance for social and cognitive development. In order to investigate how maternal care influences adaptive social behavior later in life, we here examined whether individual differences in maternal licking and grooming $(\% \mathrm{LG})$ received during the first postnatal week affect social play behavior during adolescence. We observed that \% LG received by male rats early in life correlates positively with the frequency and duration of pouncing and pinning, the two most characteristic behavioral expressions of social play behavior in rats. The latency to engage in social exploration also correlated with \%LG. In female rats we observed no correlation between \%LG and any social parameter. The data indicate that subtle variations in maternal care received early in life influence social interactions in male adolescent rats. These changes in social play likely have repercussions for the social development of male rats, suggesting that maternal care can have both direct and indirect effects on the behavioral development of the offspring.

(c) 2011 Elsevier Inc. All rights reserved.
\end{abstract}

\section{Introduction}

Early life experience has extensively been shown to affect brain development, including the central regulation of systems involved in hormone secretion (e.g. the hypothalamus-pituitary-adrenal (HPA) axis) and neurotransmission (e.g. by dopamine, serotonin), in humans as well as in rodents (examples in Refs. [1-4]). As a consequence, early life experiences have implications for behavioral function later in life. This has been studied in a controlled manner in animal models, e.g. by separating rat pups from their mother for a certain amount of time or by comparing pups receiving high as opposed to low amounts of maternal care. In several studies, early life adversity was found to increase the HPA activity in response to stress [5] and impair later life learning

\footnotetext{
* Correspondence to: L.J.M.J. Vanderschuren, Dept. of Neuroscience and Pharmacology, Rudolf Magnus Institute of Neuroscience, University Medical Center Utrecht, Universiteitsweg 100, 3584 CG Utrecht, The Netherlands. Tel.: +31 887568811. ** Correspondence to: M. Joëls, Dept. of Neuroscience and Pharmacology, Rudolf Magnus Institute, University Medical Center Utrecht, Universiteitsweg 100, 3584 CG Utrecht, The Netherlands. Tel.: +31 887568138.

E-mail addresses: 1.j.m.j.vanderschuren@umcutrecht.nl (L.J.M.J. Vanderschuren), m.joels@umcutrecht.nl (M. Joëls).
}

performance [6]. One behavioral aspect that has received considerable attention in the study of consequences of early life environmental experience is social functioning [7]. Research in primates and rodents demonstrated that lack of early social interaction of individuals with their mother and/or peers impairs social behavior in adulthood [8-10].

In rodents, social play behavior is the earliest form of social behavior that is not directed toward the mother; social play is known to be crucial for the further social development of the animal [11-14]. Social play has a high reward value and is modulated by neurotransmitter systems involved in motivation and reward, such as opioids, cannabinoids and dopamine [14-17]. In addition, brain structures part of the neural circuits of reward and motivation, such as the nucleus accumbens and the amygdala, have been implicated in the regulation of social play behavior $[14,15,18]$. In the maternal care model for early life environment in rodents, which investigates the effects of natural variations in maternal care between different litters [19], animals which received low compared to high amounts of licking and grooming (LG) early in life displayed increased social play behavior in adolescence and elevated dopamine responses to stress in the medial prefrontal cortex in adulthood [20]. In addition, Low compared to High LG offspring showed enhanced HPA axis responses to stress and increased levels of anxiety and fearfulness [21-23]. 
Interestingly, recent studies have shown that even within one litter there might be considerable variation in the amount of care bestowed by the mother on individual pups, with long-lasting consequences for brain and behavior [24]. In view of this, and the importance of social play behavior for social development, we here investigated whether variations in the amount of maternal care received by individual pups within a litter influences adolescent social play behavior. This paradigm allowed us to test both males and females along a continuum of maternal care scores with the least possible influence of genetic background.

\section{Materials and methods}

The animals used in this study were bred in our facility, and kept on a $12 \mathrm{~h}$ light/dark schedule (lights on at 8:00 h) until weaning at postnatal day 24 . At that time they were moved to a different room with a reversed light cycle (lights on at 21:00 h). Rats are more active during the dark phase of the day-night cycle, and will therefore display most play behavior during this phase (see e.g. Ref [25]). This seems to relate to light conditions rather than the time of day [26]. Since the animals were allowed an 11-day adaptation period between reversal of the day-night cycle and testing for social play, any short-term effects of changing their circadian rhythm are not likely to have confounded the results. During the entire experiment, temperature and humidity were maintained at $20-22^{\circ} \mathrm{C}$ and 40 $60 \%$ respectively, and food and water were available ad libitum.

\subsection{Maternal care}

Male and female outbred Long Evans rats were purchased from Harlan (Indianapolis, US) at approximately 2.5 months of age and allowed to habituate to the animal facility. Then, two females were housed with one male for 1 week to allow mating, and after another week of paired-housing, the females were placed separately in large observation cages $\left(30 \times 55 \times 45 \mathrm{~cm}^{3}\right)$. Maternal care observations commenced on postnatal day 1 (PND1; with PND0 being the day of birth), after culling the litters to eight pups (preferably four males and four females), as described before [24]. Briefly, maternal behavior was scored every $3 \mathrm{~min}$ during five one-hour observation sessions daily (7:00, 10:00, 13:00, 17:00 and 20:00 h) for 7 days, resulting in a total of 700 observations for each litter. Several specific maternal behaviors were scored, including licking and grooming (LG), particularly toward individual pups within each litter. In order to be able to identify the pup that underwent licking and grooming, all pups were uniquely marked every morning until weaning with a non-scenting, non-toxic surgical marker (Codman, Johnson \& Johnson, Brunswick, $\mathrm{NY}$ ). We were able to distinguish which pup was being licked and groomed in about $60 \%$ of the cases, and since this percentage varied slightly between litters, we corrected for this with the following equation: (\% individual LG observed) / (\% total LG identified)*100\%. As described before, we did not find any effects of the marking procedure or the markings per se on the licking behavior of the dam [24].

On PND24, the pups were weaned, ear-punched and put on a reversed $12 \mathrm{~h}$ day/night regimen. They were group-housed ( 4 animals per cage) with their same-sex littermates until testing in the social play paradigm on PND35.

All experimental procedures used in this study were approved by the animal ethical and welfare committee of the University of Amsterdam.

\subsection{Social play behavior}

Twenty females and 22 males were selected for further investigations. These (same-sex) animals were paired according to their individual \%LG, in such a way that animals with comparable LG scores were tested together. Six animals could not be matched with an

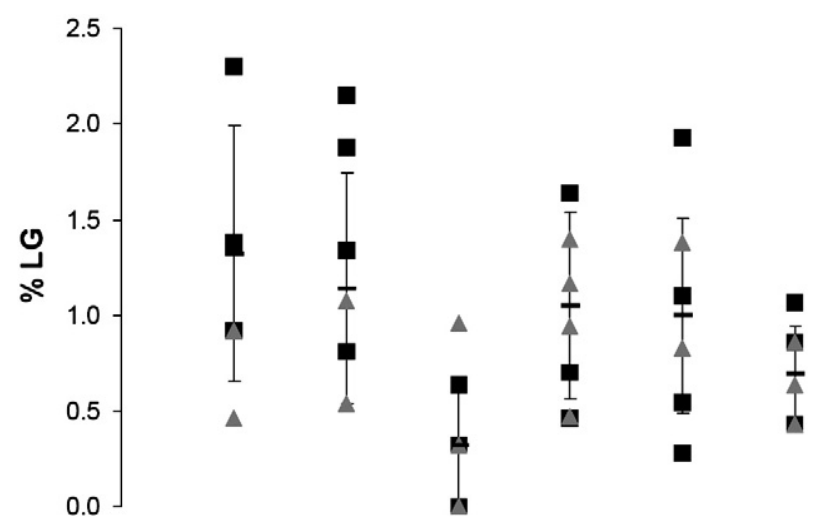

Fig. 1. Licking/grooming scores of pups in all litters used for the current study. Each column represents a litter and each data point represents a pup. Substantial within-litter variation exists in the amount of licking and grooming that individual pups receive. Error bars depict one SD above and below the litter mean (horizontal bar). Black squares represent males, gray triangles represent females.

animal of the same sex and similar \%LG and were thus not included in the study. Habituation and behavioral testing were performed as described previously [27], and occurred in the first 2 to $4 \mathrm{~h}$ of the dark phase (in red light conditions), when cage activity is high $[28,29]$. For 10 min per day on the 2 days prior to testing, the animals were individually habituated to the test cage, which consisted of a square black plastic cage $\left(40 \times 40 \times 40 \mathrm{~cm}^{3}\right)$ with sawdust. The animals were tested on PND35, which is considered to fall well into the age span that covers adolescence in the rat and is associated with high levels of social play behavior [28,30-32].

On the test day, the animals were first socially isolated for $3 \mathrm{~h}$ to enhance their motivation to engage in play behavior during the test, and subsequently pairs of animals with similar LG scores were put in the test cage for $15 \mathrm{~min}$ and allowed to interact. The animals did not have previous common social experience (i.e. they did not belong to the same litter), except for two pairs; excluding these two pairs from the analysis did not influence the data in any respect (data not shown) and therefore they were included in the final data representation. In none of the pairs the animals differed more than $10 \%$ in body weight. Each test session was recorded for later offline analysis. Behavior was assessed per pair of animals using the Observer 3.0 software (Noldus Information Technology B.V., The Netherlands). The frequency, duration of, and latency to the first occurrence of the following behavioral elements were scored [11,12,14,16]: 1) pinning:

Table 1

Correlations between individual \%LG received during the first postnatal week and adolescent social play behaviour in pairs of males $\left(n=11\right.$; $\left.{ }^{*} p<0.05\right)$. The data points for the correlations indicated in bold are shown in Fig. 2.

\begin{tabular}{lrll}
\hline Parameter & $\mathrm{r}=$ & $\mathrm{p}=$ & Mean \pm SEM \\
\hline Pouncing & & & \\
Latency & -.170 & .618 & $183.1 \pm 26.4 \mathrm{~s}$ \\
Frequency & $\mathbf{. 6 3 7}$ & $\mathbf{. 0 3 5}$ & $23.5 \pm 3.3$ times \\
$\quad$ Duration & $\mathbf{. 6 7 2}$ & $\mathbf{. 0 2 3}^{*}$ & $16.3 \pm 2.5 \mathrm{~s}$ \\
Pinning & & & \\
Latency & -.211 & .534 & $234.0 \pm 32.4 \mathrm{~s}$ \\
Frequency & $\mathbf{. 6 0 8}$ & $\mathbf{. 0 4 7}^{*}$ & $10.8 \pm 3.0$ times \\
Duration & $\mathbf{. 7 6 3}$ & $\mathbf{. 0 0 6}^{*}$ & $21.8 \pm 7.0 \mathrm{~s}$ \\
Social exploration & & & \\
Latency & $\mathbf{. 7 2 4}$ & $\mathbf{. 0 1 2}$ & $5.23 \pm 1.0 \mathrm{~s}$ \\
Frequency & -.343 & .302 & $82.5 \pm 4.5$ times \\
Duration & -.179 & .599 & $386.0 \pm 17.2 \mathrm{~s}$ \\
\hline
\end{tabular}


one animal lying with its dorsal surface on the floor with the other animal standing over it. This is the most characteristic posture in social play in rats, that occurs when one animal is solicited to play by its test partner and rotates to its dorsal surface to prolong the playful interaction; 2) pouncing: this is an index of play solicitation, i.e., one animal is soliciting the other to play, by attempting to nose or rub the nape of the neck of the test partner; 3) social exploration: sniffing any part of the body of the test partner, including the anogenital area.

\subsection{Statistical analysis}

Statistical analyses were conducted using SPSS 11.0 for Windows. All correlations were tested using linear regression with \%LG as the

A

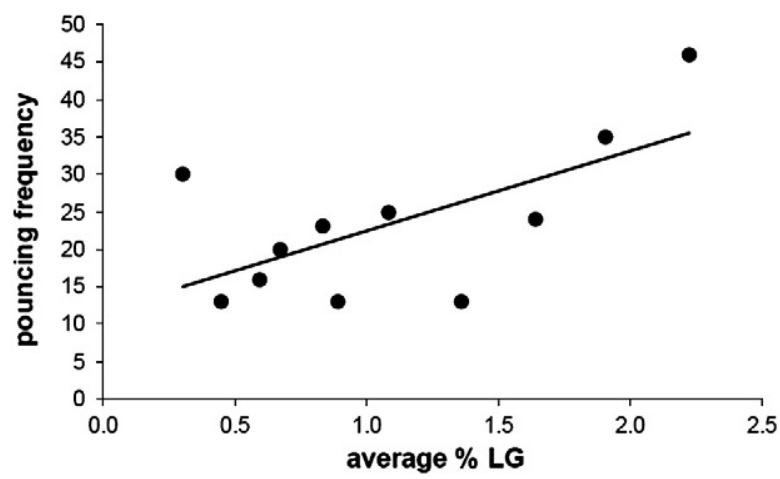

C

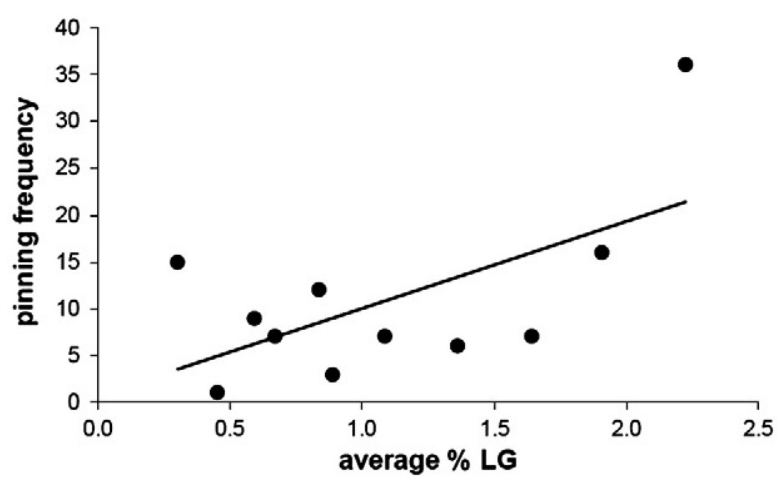

independent (predictor) variable. Male and female data were analyzed separately.

\section{Results}

\subsection{Maternal behavior}

In this study, we monitored maternal care in the offspring of six lactating dams, from PND1 to PND7. We assessed the percentage of time they spent licking and grooming (\%LG) each individual pup in their litters. As shown in Fig. 1, the \%LG received by individual pups varied considerably between pups within litters (range $0.00 \%$ to $2.30 \% \mathrm{LG}$; mean $\% \mathrm{LG}=0.93 \%, \mathrm{SD}=0.58, \mathrm{n}=48$ ). In general, male pups $(\mathrm{n}=27)$ received significantly more $L G$ than females $(\mathrm{n}=21$; $\mathrm{p}=0.047$ ), in agreement with earlier reports $[24,33]$.
B

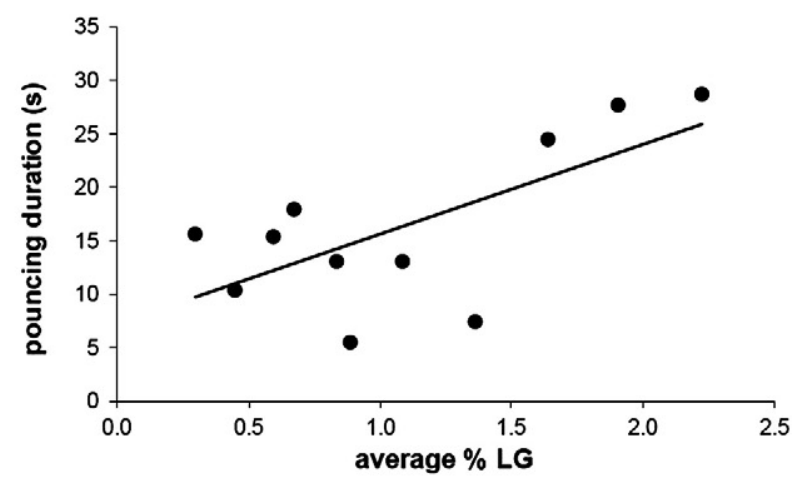

D

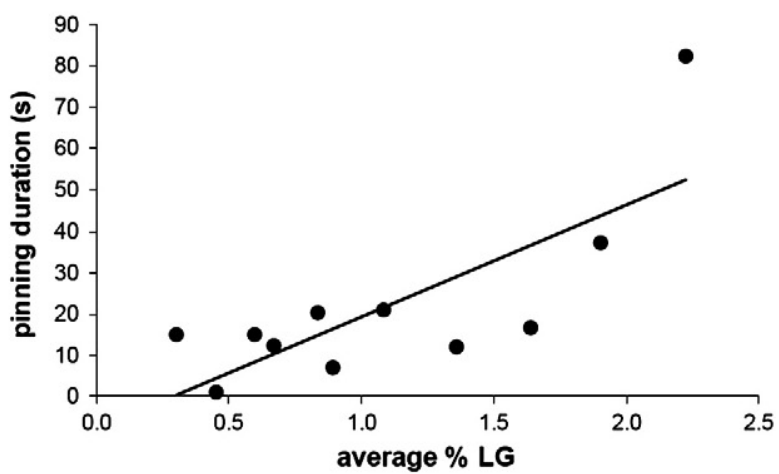

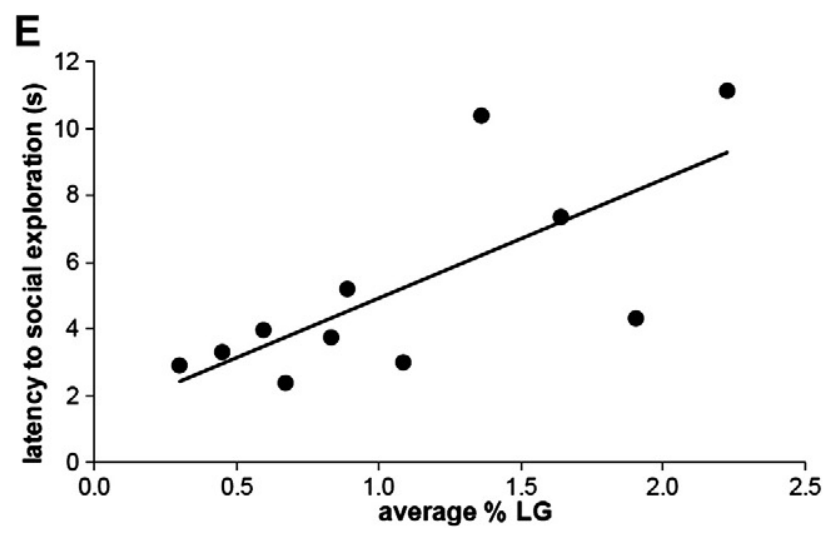

Fig. 2. Male offspring that received higher levels of maternal LG show more adolescent play behavior than male offspring with lower LG scores. There was a positive correlation between \%LG (X-axis) and both frequency (A; number of times during the 15 minute observation period) and duration (B; cumulative time in seconds during the 15 minute observation period) of pouncing, as well as the frequency (C) and duration (D) of pinning. However, the latency to start social exploration was increased in High LG animals (E; in seconds). Data are based on 11 pairs. For correlational analysis of all parameters see Table 1. 
Table 2

Correlations between individual \%LG received during the first postnatal week and adolescent social play behaviour in pairs of females $(n=10)$ during the 15 minute observation period. None of the correlations was significant.

\begin{tabular}{lrll}
\hline Parameter & $\mathrm{r}=$ & $\mathrm{p}=$ & Mean \pm SEM \\
\hline Pouncing & & & \\
Latency & .009 & .983 & $285.0 \pm 101.0 \mathrm{~s}$ \\
Frequency & -.122 & .738 & $21.7 \pm 7.1$ times \\
$\quad$ Duration & -.207 & .567 & $15.6 \pm 4.7 \mathrm{~s}$ \\
Pinning & & & \\
Latency & .316 & .446 & $303.9 \pm 99.3 \mathrm{~s}$ \\
Frequency & -.095 & .795 & $11.8 \pm 5.1$ times \\
Duration & -.069 & .850 & $23.1 \pm 10.0 \mathrm{~s}$ \\
Social exploration & & & \\
$\quad$ Latency & -.192 & .595 & $3.8 \pm 0.9 \mathrm{~s}$ \\
Frequency & -.132 & .715 & $77.5 \pm 10.3$ times \\
Duration & .117 & .748 & $317.8 \pm 18.2 \mathrm{~s}$ \\
\hline
\end{tabular}

\subsection{Social play behavior}

In the current study we tested 10 pairs of females and 11 pairs of males with comparable LG scores to examine if individual variations in the amount of LG received during the first postnatal week affected adolescent social play behavior. As an index for early life background, we used the average \%LG of each pair.

In males, significant positive correlations emerged between \%LG and both the frequency (Fig. 2A) and duration (Fig. 2B) of pouncing. Similarly, a positive and significant correlation was observed between \%LG received early in life and the frequency (Fig. 2C) and duration (Fig. 2D) of pinning (see also Table 1). Thus, male rat pairs with higher average LG scores exhibited more social play behavior during the 15 min session compared to pairs that received lower levels of maternal licking and grooming. However, males on the high end of the LG scale also showed a significantly increased latency to first social exploration compared to males with a lower \%LG (Fig. 2E, Table 1). None of the other parameters, i.e. the latency to pounce and pin and the frequency and duration of social exploration, correlated significantly with \%LG in the males (Table 1 ).

The direction in which aspects of social play by females related to \%LG received early in life was generally opposite to that seen in males. In females, though, none of the play behavior parameters that were assessed correlated significantly with \%LG. Also, in general, they exhibited a lower amount of play behavior than the males (see Table 2).

We considered the possibility that the lower amounts of LG received early in life by females might explain the lack of correlation with social play later on, rather than inherent differences in social play behavior between male and female rats. To test this, we applied a median split analysis, examining correlations separately in two groups of animals, that is in animals (male or female) with either a low LG score $(<0.93 \%)$ or a high LG score $(>0.93 \%)$. In the former group we did not observe a significant correlation between \%LG and any of the social play parameters ( $p$-values for all parameters $>0.25$ ). In the group with high LG scores we generally observed much higher correlation coefficients. This resulted in a significant ( $p=0.048$ ) positive correlation between \%LG and frequency of boxing, a near-significant $(\mathrm{p}=0.069)$ positive correlation between \%LG and latency to engage in first social exploration (as was seen when analyzing males only), and a trend toward a positive correlation between \%LG and duration of pouncing ( $p=0.13$; comparable to what was observed in males) as well as a trend toward a negative correlation between \%LG and latency in boxing $(\mathrm{p}=0.12)$.

\section{Discussion}

In the present study, we investigated the effects of individual variation in \%LG received early in life on social behavior in adolescent rat offspring. We found that male adolescents with higher LG scores exhibited more social play behavior than their siblings with lower \%LG, whereas in females \%LG did not correlate with the amount of social play behavior.

Earlier studies have described the effect of early life environment on adolescent social play behavior. Artificially reducing the amount of maternal LG for example resulted in increased levels of social play in the (male) offspring [34,35]. Additionally, one study, in which litters that on average received very low as compared to high amounts of care were compared, reported increased play behavior in offspring from Low LG compared to High LG dams [29]. This contrasts with our observations based on the \%LG received by individual pups, taking the entire range of LG behavior into account.

There are several explanations for the discrepancy between our and the previous study addressing the influence of maternal care and social play during adolescence. First, the paradigm to study social play was different between the studies. Parent and Meaney housed pups with different maternal care backgrounds (i.e. High LG and Low LG) for several weeks in mixed-gender groups of 8, and observed the play behavior for each pup individually, irrespective of its play partner. This protocol likely created an enrichment of the environment, to which Low LG offspring are known to be more sensitive [36,37]. Indeed, this was suggested by these authors as the reason for the elevated levels of play behavior in Low LG offspring. By contrast, in our setup, we used a brief period of social isolation to evoke reliable levels of social play that can be both positively and negatively modulated by neuropharmacological interventions (e.g. 27,38,39). Therefore, our setup was more directed at taxing differences in the level of social motivation of the animals. Furthermore, we tested animals in pairs of the same sex, maternal care background and comparable weight because of the reciprocity and contagious nature of social play behavior [40], without the possible influence of environmental enrichment. In nearly all cases, the two animals in a pair originated from different litters and were not housed together. This excluded the influence of established social hierarchy as much as possible, although it cannot be excluded that such differences existed despite our experimental protocol.

Secondly, it is possible that stress plays a role in the reduced social play behavior in rats with lower LG scores [28]. Despite being habituated to the test box, encountering an unfamiliar animal in the test situation, and especially being socially isolated prior to testing, might induce a stronger stress response in animals which received low amounts of LG early in life. At this moment this remains speculative, because we did not measure peak corticosterone levels after stress in our animals; moreover, only effects of repeated or chronic social isolation on HPA reactivity have been described (e.g. 41,42).

Thirdly, we cannot exclude that genetic background may have influenced the earlier observations. Cross-fostering experiments demonstrated that many of the consequences of early life stress seen when comparing entire litters critically depend on maternal behavior rather than genetic background $[22,43]$. However, in the case of social play behavior cross-fostering control experiments have not been carried out. In our model, where the \%LG is used as an index regardless of maternal background, this factor does not play a significant role.

Finally, we analyzed social play separately for female and male rats. The relationship between \%LG received early in life and aspects of adolescent social play differed between the two sexes, as \%LG was not significantly correlated with social play in females. It is well-known that social play behavior differs both quantitatively (i.e. males play more than females) and qualitatively (i.e. the structure and ontogenetic development of playful interactions) between males and females $[44,45]$. The present data add to this difference that social play behavior in adolescent females may be less sensitive to early life environment than play behavior in males; these differences between the sexes may also have influenced the observations 
of the previous study, in which males and females were housed together.

The determining factor in the male-female difference seems to be that females received lower amounts of LG early life; a median-split analysis supports the view that correlation between \%LG and play behavior can reach significance only in animals that have received a relatively high amount of LG. It seems unlikely that any 'female-specific' aspects of social play - and putatively correlated with \%LG - were missed in our present analysis. Thus, while social play differs between male and female rats in both qualitative and quantitative ways $[44,45]$, the qualitative differences, in terms of the use of different defense tactics during social play, do not emerge until around PD40, and appear to be associated with the onset of sexual maturation [46]. Therefore, at the time of testing in the present study (PD 35), the differences between males and females are for the most part quantitative [47].

Interestingly, whereas the amount of social play correlated positively with \%LG in male rats, a high-LG background resulted in a long latency to social exploration, which is known to precede the onset of playful interactions [45]. Even though these latencies were generally quite low (i.e. between 2 and $12 \mathrm{~s}$ after the start of the test), this indicates that males that received a high \%LG were somewhat slower to initiate the social interaction, but once initiated, they engaged in a more intense playful interaction. For this reason, the longer latency to initiate the social interaction in high \%LG males is not likely the result of decreased social interest. Rather, it shows that these animals took somewhat longer to engage in social behavior after being placed in the test environment, suggesting that these animals took slightly more time to evaluate the safety of the test cage.

In conclusion, our results indicate that in male but not female rats, the amount of care received by an individual rat from its mother predicts the amount of subsequent adolescent social play behavior. The findings in males are in accordance with recent data showing that neonatal handling stimulation fuels playfulness in adolescent rats, as measured by pin and dorsal contact episodes [48,49]. This does not necessarily mean that LG causes social play to develop; clearly, there are many other factors involved (as apparent from the overlap in individual values of LG and play). The lack of correlation between LG and social play in females suggests that the development of social play in male and female rats is facilitated through different mechanisms. This is not purely a quantitative issue, but possibly also relates to later-developing (around PND40) qualitative differences in social play. Thus, we cannot exclude that maternal care for female pups serves to facilitate the development of other, more female-specific social behaviors that occur later in life. Collectively, these data indicate that maternal care has both direct and indirect effects on the behavior of the offspring. Since social play facilitates social and cognitive development [11-14], the present data suggest that by evoking greater amounts of social play, higher levels of maternal care may facilitate the further social and cognitive development at least in male offspring. In addition, social play in adolescence is a form of social reward [11,12,14-17], suggesting that other aspects of reward and motivation in adolescence also depend on early life environment, as was previously already observed in adult animals [50,51]. If so, this could be relevant for the vulnerability of adolescent individuals to reward-associated psychopathology such as depression and addiction. This is compatible with the view that a high-caring early life background optimally prepares individuals for a matching positive social environment later in life, but that psychopathology may develop in case of a mismatch between early and later life social environment.

\section{Acknowledgments}

The authors thank Noortje van der Knaap and Daniëlle de Jong for their help with maternal care observations. This work was supported by Human Frontiers Science Program grant \#RGP0039/2006.

\section{References}

[1] Heim C, Newport DJ, Mletzko T, Miller AH, Nemeroff CB. The link between childhood trauma and depression: insights from HPA axis studies in humans. Psychoneuroendocrinology 2008;33(6):693-710.

[2] Matthews K, Dalley JW, Matthews C, Tsai TH, Robbins TW. Periodic maternal separation of neonatal rats produces region- and gender-specific effects on biogenic amine content in postmortem adult brain. Synapse 2001;40(1):1-10.

[3] Pryce CR, Ruedi-Bettschen D, Dettling AC, Weston A, Russig H, Ferger B, et al. Long-term effects of early-life environmental manipulations in rodents and primates: potential animal models in depression research. Neurosci Biobehav Rev 2005;29(4-5):649-74.

[4] Tarullo AR, Gunnar MR. Child maltreatment and the developing HPA axis. Horm Behav 2006;50(4):632-9.

[5] Ladd CO, Huot RL, Thrivikraman KV, Nemeroff CB, Plotsky PM. Long-term adaptations in glucocorticoid receptor and mineralocorticoid receptor mRNA and negative feedback on the hypothalamo-pituitary-adrenal axis following neonatal maternal separation. Biol Psychiatry 2004;55(4):367-75.

[6] Oomen CA, Soeters H, Audureau N, Vermunt L, van Hasselt FN, Manders EM, et al. Severe early life stress hampers spatial learning and neurogenesis, but improves hippocampal synaptic plasticity and emotional learning under high-stress conditions in adulthood. J Neurosci 2010;30(19):6635-45.

[7] Green MF, Horan WP. Social cognition in schizophrenia. Curr Dir Psychol Sci 2010;19(4):243-8.

[8] Franklin TB, Linder N, Russig H, Thony B, Mansuy IM. Influence of early stress on social abilities and serotonergic functions across generations in mice. PLoS One 2011;6(7):e21842.

[9] Stevens HE, Leckman JF, Coplan JD, Suomi SJ. Risk and resilience: early manipulation of macaque social experience and persistent behavioral and neurophysiological outcomes. J Am Acad Child Adolesc Psychiatry 2009;48(2):114-27.

[10] Young LD, Suomi SS, Harlow HF, McKinney Jr WT. Early stress and later response to separation in rhesus monkeys. Am J Psychiatry 1973;130(4):400-5.

[11] Panksepp J, Siviy S, Normansell L. The psychobiology of play: theoretical and methodological perspectives. Neurosci Biobehav Rev 1984;8(4):465-92.

[12] Pellis SM, Pellis VC. The playful brain: venturing to the limits of neuroscience. Oxford: Oneworld Publications; 2009.

[13] Spinka M, Newberry RC, Bekoff M. Mammalian play: training for the unexpected. Q Rev Biol 2001;76(2):141-68

[14] Vanderschuren LJ, Niesink RJ, Van Ree JM. The neurobiology of social play behavior in rats. Neurosci Biobehav Rev 1997;21(3):309-26.

[15] Siviy SM, Panksepp J. In search of the neurobiological substrates for social playfulness in mammalian brains. Neurosci Biobehav Rev 2011;35(9):1821-30.

[16] Trezza V, Baarendse PJ, Vanderschuren LJ. The pleasures of play: pharmacological insights into social reward mechanisms. Trends Pharmacol Sci 2010;31(10):463-9.

[17] Vanderschuren LJ. How the brain makes play fun. Am J Play 2010;2:315-37.

[18] Trezza V, Damsteegt R, Achterberg EJ, Vanderschuren LJ. Nucleus accumbens muopioid receptors mediate social reward. J Neurosci 2011;31(17):6362-70.

[19] Champagne FA, Francis DD, Mar A, Meaney MJ. Variations in maternal care in the rat as a mediating influence for the effects of environment on development. Physiol Behav 2003;79(3):359-71.

[20] Zhang TY, Chretien P, Meaney MJ, Gratton A. Influence of naturally occurring variations in maternal care on prepulse inhibition of acoustic startle and the medial prefrontal cortical dopamine response to stress in adult rats. J Neurosci 2005;25(6):1493-502.

[21] Caldji C, Tannenbaum B, Sharma S, Francis D, Plotsky PM, Meaney MJ. Maternal care during infancy regulates the development of neural systems mediating the expression of fearfulness in the rat. Proc Natl Acad Sci U S A 1998;95(9):5335-40.

[22] Francis D, Diorio J, Liu D, Meaney MJ. Nongenomic transmission across generations of maternal behavior and stress responses in the rat. Science 1999;286(5442): 1155-8.

[23] Liu D, Diorio J, Tannenbaum B, Caldji C, Francis D, Freedman A, et al. Maternal care, hippocampal glucocorticoid receptors, and hypothalamic-pituitary-adrenal responses to stress. Science 1997;277(5332):1659-62.

[24] Van Hasselt FN, Cornelisse S, Zhang TY, Meaney MJ, Velzing EH, Krugers HJ and Joels M. Adult hippocampal glucocorticoid receptor expression and dentate synaptic plasticity correlate with maternal care received by individuals early in life. Hippocampus in press.

[25] Schneider M, Koch M. Deficient social and play behavior in juvenile and adult rats after neonatal cortical lesion: effects of chronic pubertal cannabinoid treatment. Neuropsychopharmacology 2005;30(5):944-57.

[26] Vanderschuren LJ, Spruijt BM, Hol T, Niesink RJ, Van Ree JM. Sequential analysis of social play behavior in juvenile rats: effects of morphine. Behav Brain Res 1995;72(1-2):89-95.

[27] Trezza V, Vanderschuren LJ. Bidirectional cannabinoid modulation of social behavior in adolescent rats. Psychopharmacology (Berl) 2008;197(2):217-27.

[28] Klein ZA, Padow VA, Romeo RD. The effects of stress on play and home cage behaviors in adolescent male rats. Dev Psychobiol 2010;52(1):62-70.

[29] Parent CI, Meaney MJ. The influence of natural variations in maternal care on play fighting in the rat. Dev Psychobiol 2008;50(8):767-76.

[30] Auger AP, Olesen KM. Brain sex differences and the organisation of juvenile social play behaviour. J Neuroendocrinol 2009;21(6):519-25.

[31] Panksepp J. The ontogeny of play in rats. Dev Psychobiol 1981;14(4):327-32.

[32] Spear LP. The adolescent brain and age-related behavioral manifestations. Neurosci Biobehav Rev 2000;24(4):417-63.

[33] Moore CL, Morelli GA. Mother rats interact differently with male and female offspring. J Comp Physiol Psychol 1979;93(4):677-84. 
[34] Birke LI, Sadler D. Differences in maternal behavior of rats and the sociosexual development of the offspring. Dev Psychobiol 1987;20(1):85-99.

[35] Moore CL, Power KL. Variation in maternal care and individual differences in play, exploration, and grooming of juvenile Norway rat offspring. Dev Psychobio 1992;25(3):165-82.

[36] Bredy TW, Humpartzoomian RA, Cain DP, Meaney MJ. Partial reversal of the effect of maternal care on cognitive function through environmental enrichment. Neuroscience 2003;118(2):571-6.

[37] Bredy TW, Zhang TY, Grant RJ, Diorio J, Meaney MJ. Peripubertal environmental enrichment reverses the effects of maternal care on hippocampal development and glutamate receptor subunit expression. Eur J Neurosci 2004;20(5):1355-62.

[38] Niesink RJ, Van Ree JM. Involvement of opioid and dopaminergic systems in isolation-induced pinning and social grooming of young rats. Neuropharmacology 1989;28(4):411-8.

[39] Vanderschuren LJ, Trezza V, Griffioen-Roose S, Schiepers OJ, Van Leeuwen N, De Vries TJ, et al. Methylphenidate disrupts social play behavior in adolescent rats. Neuropsychopharmacology 2008;33(12):2946-56.

[40] Pellis SM, McKenna MM. Intrinsic and extrinsic influences on play fighting in rats: effects of dominance, partner's playfulness, temperament and neonatal exposure to testosterone propionate. Behav Brain Res 1992;50(1-2):135-45.

[41] Van den Berg CL, Hol T, Van Ree JM, Spruijt BM, Everts H, Koolhaas JM. Play is indispensable for an adequate development of coping with social challenges in the rat. Dev Psychobiol 1999;34(2):129-38.

[42] Weintraub A, Singaravelu J, Bhatnagar S. Enduring and sex-specific effects of adolescent social isolation in rats on adult stress reactivity. Brain Res 2010;1343:83-92.
[43] Caldji C, Diorio J, Meaney MJ. Variations in maternal care alter GABA(A) receptor subunit expression in brain regions associated with fear. Neuropsychopharmacology 2003;28(11):1950-9.

[44] Meaney MJ. The sexual differentiation of social play. Psychiatr Dev 1989;7(3): 247-61.

[45] Pellis SM, Field EF, Smith LK, Pellis VC. Multiple differences in the play fighting of male and female rats. Implications for the causes and functions of play. Neurosci Biobehav Rev 1997;21(1):105-20.

[46] Pellis SM, Pellis VC, McKenna MM. Feminine dimension in the play fighting of rats (Rattus norvegicus) and its defeminization neonatally by androgens. J Comp Psychol 1994;108(1):68-73.

[47] Meaney MJ, Stewart J. Neonatal-androgens influence the social play of prepubescent rats. Horm Behav 1981;15(2):197-213.

[48] Aguilar R, Caramés JM, Espinet A. Effects of neonatal handling on playfulness by means of reversal of the desire to play in rats (Rattus norvegicus). J Comp Psychol 2009;123(4):347-56.

[49] Siviy SM, Harrison KA. Effects of neonatal handling on play behavior and fear towards a predator odor in juvenile rats (Rattus norvegicus). J Comp Psychol 2008; $122: 1-8$

[50] Lomanowska AM, Lovic V, Rankine MJ, Mooney SJ, Robinson TE, Kraemer GW. Inadequate early social experience increases the incentive salience of rewardrelated cues in adulthood. Behav Brain Res 2011;220(1):91-9.

[51] Ruedi-Bettschen D, Pedersen EM, Feldon J, Pryce CR. Early deprivation under specific conditions leads to reduced interest in reward in adulthood in Wistar rats. Behav Brain Res 2005;156(2):297-310. 